See Article page 1.

\section{Commentary: Location, location, location-proximal right subclavian cannulation for thoracic aortic surgery}

\author{
Keith A. Dufendach, MD, ${ }^{a}$ and Danny Chu, $\mathrm{MD}^{\mathrm{a}, \mathrm{b}}$
}

Arterial cannulation during surgical management of the thoracic aorta represents a substantial challenge due to the wide variety of pathologies encountered and the need for both cerebral and systemic perfusion during the course of surgery. Numerous cannulation strategies have been described and must be tailored to individual patient anatomy. Regesta and colleagues ${ }^{1}$ present their technique and results of percutaneous proximal right subclavian arterial cannulation using an extended neck incision and Seldinger technique. The technique was successfully employed in 44 consecutive patients with many types of thoracic aortic pathology, including 29 patients $(65.9 \%)$ with type A aortic dissection (TAAD). This technique allows for all types of repair, including total arch replacement with continuous unilateral antegrade cerebral perfusion (ACP). Outcomes were excellent using this strategy as measured by a $6.8 \%$ overall mortality $(\mathrm{n}=3)$ and permanent neurological dysfunction rate of $6.8 \%(n=3)$. Notably, all deaths occurred following TAAD repair, and of those who developed permanent neurologic dysfunction, 2 had preoperative neurologic symptoms related to TAAD and 1 developed paraplegia after thoracic endografting during a frozen elephant trunk procedure. These results are in line with currently held standards for thoracic aortic surgery at experienced centers. ${ }^{2,3}$

From the a Division of Cardiac Surgery, Department of Cardiothoracic Surgery, University of Pittsburgh School of Medicine, Pittsburgh, Pa; and ${ }^{\mathrm{b}}$ University of Pittsburgh Medical Center Heart and Vascular Institute, Pittsburgh, Pa.

Disclosures: Dr Chu is an international proctor/consultant for the Japanese Organization for Medical Device Development, Inc, on the faculty for The Osler Institute, and a journal editor for Wolters Kluwer Health. The other author reported no conflicts of interest.

The Journal policy requires editors and reviewers to disclose conflicts of interest and to decline handling or reviewing manuscripts for which they may have a conflict of interest. The editors and reviewers of this article have no conflicts of interest.

Received for publication April 29, 2021; revisions received April 29, 2021; accepted for publication May 3, 2021; available ahead of print May 5, 2021.

Address for reprints: Danny Chu, MD, Division of Cardiac Surgery, Department of Cardiothoracic Surgery, University of Pittsburgh School of Medicine, 200 Lothrop

St, Suite C-700, Pittsburgh, PA 15213 (E-mail: chud@upmc.edu).

JTCVS Techniques 2021;8:7-8

2666-2507

Copyright (C) 2021 The Author(s). Published by Elsevier Inc. on behalf of The American Association for Thoracic Surgery. This is an open access article under the CC BY-NC-ND license (http://creativecommons.org/licenses/by-nc-nd/4.0/)

https://doi.org/10.1016/j.xjtc.2021.05.001

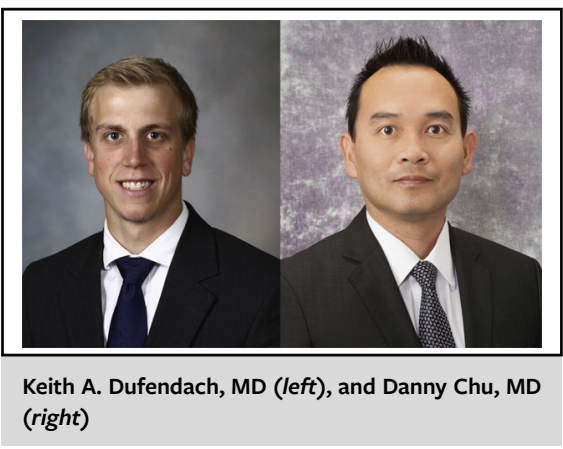

CENTRAL MESSAGE

Proximal right subclavian arterial cannulation via Seldinger technique offers the benefits of expeditious subclavian arterial cannulation with minimal risks.

This study adds to the armamentarium of cannulation strategies for patients undergoing thoracic aortic surgery and provides a rapid and reliable method of arterial cannulation. The technique is well described and could easily be replicated by a cardiac surgeon with aortic expertise. It avoids the risks of retrograde embolism or brachial plexus injury associated with either peripheral femoral arterial cannulation or distal right subclavian cannulation through a separate incision. Additionally, proximal subclavian arterial cannulation reduces, although does not eliminate, risks associated with innominate arterial involvement during TAAD repair. ${ }^{4}$

Despite a well-written report on their technique, there are important caveats that must be discussed. Firstly, the risk of clinically significant injury to the vagus nerve or its branches cannot be ignored. The authors do not report any cases of vagus nerve or recurrent laryngeal nerve injury in their series, for which they should be commended. However, were the technique to be more widely adopted, these complications are likely to occur. Although clinically significant postoperative right subclavian artery stenosis did not occur in this series, this potential complication may be more evident in patients with a small-diameter subclavian artery. Additionally, the authors are quick to dismiss the technique of central aortic cannulation due to the need for a second cannula for ACP and inability to cannulate the aorta in the case of TAAD. However, central aortic cannulation has been shown, even in TAAD, to be a rapid and reliable technique that does not require additional incisions. ${ }^{5}$ The technique allows for both ACP and retrograde 
cerebral perfusion, which may be advantageous in certain cases. ${ }^{5-7}$ Regardless of arterial cannulation strategy, surgeons should be encouraged to develop a standardized approach to cannulation that is rapid, reliable, and safe for patients and continue to adapt based on updated evidence.

\section{References}

1. Regesta T, Cavozza C, Campanella A, Pellegrino P, Gherli R, Maj G, et al. Direct proximal right subclavian artery cannulation during surgery of the thoracic aorta. J Thorac Cardiovasc Surg Tech. 2021;8:1-6.

2. Evangelista A, Isselbacher EM, Bossone E, Gleason TG, Eusanio MD, Sechtem U, et al. Insights from the International Registry of Acute Aortic Dissection: a 20-year experience of collaborative clinical research. Circulation. 2018;137:1846-60.
3. Inoue Y, Matsuda H, Uchida K, Komiya T, Koyama T, Yoshino H, et al. Analysis of acute type A aortic dissection in Japan Registry of Aortic Dissection (JRAD). Ann Thorac Surg. 2020;110:790-8.

4. Rylski B, Czerny M, Beyersdorf F, Kari FA, Siepe M, Adachi H, et al. Is right axillary artery cannulation safe in type A aortic dissection with involvement of the innominate artery? J Thorac Cardiovasc Surg. 2016;152:801-7.e1.

5. Dufendach KA, Sultan I, Gleason TG. Distal extent of surgery for acute type A aortic dissection. Oper Tech Thorac Cardiovasc Surg. 2019;24:82-102.

6. Trivedi D, Navid F, Balzer JR, Joshi R, Lacomis JM, Jovin TG, et al. Aggressive aortic arch and carotid replacement strategy for type A aortic dissection improves neurologic outcomes. Ann Thorac Surg. 2016;101:896-903.

7. Leshnower BG, Rangaraju S, Allen JW, Stringer AY, Gleason TG, Chen EP. Deep hypothermia with retrograde cerebral perfusion versus moderate hypothermia with antegrade cerebral perfusion for arch surgery. Ann Thorac Surg. 2019;107: 1104-10. 